\title{
In vitro effects of citral on Trypanosoma cruzi metacyclogenesis
}

\author{
Josiane Cardoso, Maurilio José Soares/+ \\ Instituto Carlos Chagas-Fiocruz, Rua Prof. Algacyr Munhoz Mader 3775, 81350-010 Curitiba, PR, Brasil
}

\begin{abstract}
Citral, the main constituent of lemongrass (Cymbopogon citratus) essential oil, was added to Trypanosoma cruzi cultures grown in TAU3AAG medium to observe the effect on the epimastigote-to-trypomastigote differentiation process (metacyclogenesis). Our results showed that citral $(20 \mu \mathrm{g} / \mathrm{mL})$ did not affect epimastigote viability or inhibit the differentiation process. Concentrations higher than $60 \mu \mathrm{g} / \mathrm{mL}$, however, led to $100 \%$ cell death (both epimastigote and trypomastigote forms). Although epimastigotes incubated with $30 \mu \mathrm{g} / \mathrm{mL}$ citral were viable and able to adhere to the substrate, we observed around $50 \%$ inhibition in metacyclogenesis, with a calculated concentration that inhibited metacyclogenesis by $50 \%$ after $24 \mathrm{~h}\left(\mathrm{IC}_{50} / 24 \mathrm{~h}\right)$ of about $31 \mu \mathrm{g} / \mathrm{mL}$. Treatment with $30 \mu \mathrm{g} / \mathrm{mL}$ citral did not hinder epimastigote multiplication because epimastigote growth resumed when treated cells were transferred to a drugfree liver infusion tryptose culture medium. Metacyclogenesis was almost totally abolished at $40 \mu \mathrm{g} / \mathrm{mL}$ after $24 \mathrm{~h}$ of incubation. Furthermore, the metacyclic trypomastigotes obtained in vitro were similarly susceptible to citral, with an $\mathrm{IC}_{50} / 24 \mathrm{~h}$, concentration that killed $50 \%$ of the cells after $24 \mathrm{~h}$, of about $24.5 \mu \mathrm{g} / \mathrm{mL}$. Therefore, citral appears to be a good candidate as an inhibitory drug for further studies analyzing the T. cruzi metacyclogenesis process.
\end{abstract}

Key words: citral - essential oil - metacyclogenesis - Trypanosoma cruzi

Trypanosoma cruzi is a kinetoplastid flagellate protozoan that causes Chagas disease in Latin America, where 75-90 million are exposed to the infection. Studies have estimated that currently 15-16 million people are infected with this parasite (Coura \& Dias 2009). T. cruzi has a life cycle that includes invertebrate (triatomine bugs) and vertebrate (mammals) hosts. During its cycle, the parasite undergoes drastic morphological alterations in cell shape, which result in at least three major evolutive forms. Each form has adapted for living in specific environments inside the hosts. Although epimastigote forms are exclusive to the insect vector, trypomastigotes (bloodstream forms) and amastigotes (intracellular forms) are associated with vertebrate hosts (de Souza 1984).

T. cruzi differentiation from the epimastigote to the trypomastigote stage in the insect rectum (metacyclogenesis process) is critical for the generation of infective metacyclic trypomastigotes. Furthermore, intracellular differentiation from trypomastigotes to amastigotes (and then back to trypomastigotes) is essential for evading the host's immune response and maintaining the infection in the mammalian host. Therefore, studies on these processes may help to elucidate their functioning and indicate potential targets for the development of trypanocidal drugs. This is relevant because the currently available drugs (nifurtimox and benznidazole) are not fully effective and present serious, toxic side effects (Coura \& de Castro 2002, Urbina 2009).

Financial support: CAPES, CNPq, FIOCRUZ

+ Corresponding author: maurilio@tecpar.br

Received 24 June 2010

Accepted 29 September 2010
Essential oils are sources of phy totherapeutic agents that have traditionally been used by native cultures to treat infectious diseases. Their use as antimicrobial and antifungal agents has been firmly established for decades (Burt 2004). More recently, studies have shown that essential oils may also be used as anti-protozoal drugs. Indeed, essential oils have inhibitory actions against diverse parasitic protozoa, such as Plasmodium falciparum (Valentin et al. 1995), Trypanosoma brucei, Leishmania major (Mikus et al. 2000), Leishmania amazonensis (Monzote et al. 2006, Santin et al. 2009) and T. cruzi (Santoro et al. 2007a, b, c).

Interestingly, the essential oil of Cymbopogon citratus (DC) Stapf (Gramineae) has anti-fungal and antibacterial activities (Onawunmi et al. 1984, Onawunmi 1989, Ibrahim 1992, Mishra \& Dubey 1994, Viollon \& Chaumont 1994, Wannissorn et al. 1996, Cimanga et al. 2002). This essential oil has been shown to be effective against protozoa and significantly reduced the growth of Plasmodium berghei (Tchoumbougnang et al. 2005), the insect trypanosomatid Crithidia deanei (Pedroso et al. 2006), L. amazonensis (Santin et al. 2009) and all three evolutive forms of T. cruzi (Santoro et al. 2007a).

Because the $T$. cruzi differentiation process plays a major role in the life cycle of the parasite, understanding and influencing this process is a primary research interest. Citral, the main constituent of $C$. citratus (lemongrass) essential oil, showed a high activity against $T$. cruzi bloodstream trypomastigotes (Santoro et al. 2007a), with a concentration that induced $50 \%$ cell lysis $\left(\mathrm{IC}_{50}\right)$ of about $15 \mu \mathrm{g} / \mathrm{mL}$. Therefore, the present study investigated the effect of citral on the epimastigote-to-trypomastigote metacyclogenesis process of $T$. cruzi in vitro by growing the parasites in triatomine artificial urine (TAU)3AAG, which is a chemically defined medium that induces parasite differentiation (Contreras et al. 1985). 


\section{MATERIALS AND METHODS}

Drugs - Citral, an isomeric mixture of geranial and neral (Fig. 1), was purchased from Sigma (Sigma-Aldrich, St. Louis, MO, USA) and initially diluted in dimethyl sulphoxide (DMSO) at a concentration of $100 \mathrm{mg} /$ $\mathrm{mL}$. This solution was then diluted in TAU or TAU3AAG culture media to obtain a second stock solution at $1 \mathrm{mg}$ / $\mathrm{mL}$ (the DMSO was diluted to $1 \%$ ). Stock solutions were stored at $4^{\circ} \mathrm{C}$ and used within one month. Stock solutions prepared in culture media were diluted at different concentrations for the experiments $(20,40,60,80$ or $100 \mu \mathrm{g} /$ $\mathrm{mL}$ ). Under this setting, the final DMSO concentration in the assays never exceeded $0.1 \%$. Thus, the potentially toxic effects of DMSO did not affect protozoa.

Parasite - T. cruzi strain Dm28c (Contreras et al. 1988) was used in the experiments. Culture epimastigote forms were kept at $28^{\circ} \mathrm{C}$ in liver infusion tryptose (LIT) medium (Camargo 1964) supplemented with 10\% foetal bovine serum. The epimastigotes were passaged weekly.

Epimastigote-to-trypomastigote differentiation For in vitro metacyclogenesis, 5-day-old culture epimastigotes were harvested by centrifugation at $7000 \mathrm{~g}$ for $10 \mathrm{~min}$ at $10^{\circ} \mathrm{C}$. The parasites were then incubated for $2 \mathrm{~h}$ at $28^{\circ} \mathrm{C}$ at a density of $5 \times 10^{8}$ cells $/ \mathrm{mL}$ in TAU medium $(190 \mathrm{mM} \mathrm{NaCl}, 17 \mathrm{mM} \mathrm{KCl}, 2 \mathrm{mM} \mathrm{MgCl}$, $2 \mathrm{mM} \mathrm{CaCl}_{2}, 8 \mathrm{mM}$ phosphate buffer, $\mathrm{pH}$ 6.0). Thereafter, the parasites were incubated at a 1:100 dilution (final epimastigotes concentration: $5 \times 10^{6}$ cells $/ \mathrm{mL}$ ) for $96 \mathrm{~h}$ at $28^{\circ} \mathrm{C}$ in TAU3AAG medium (TAU supplemented with $10 \mathrm{mM}$ L-proline, $50 \mathrm{mM}$ L-sodium glutamate, $2 \mathrm{mM} \mathrm{L}$-sodium aspartate and $10 \mathrm{mM} \mathrm{D}$-glucose) in $25 \mathrm{~mL}$ culture flasks with a layer of culture medium that was not more than $1 \mathrm{~cm}$ in depth (Contreras et al. 1985). All experiments were performed with a final parasite concentration of $5 \times 10^{6}$ epimastigotes $/ \mathrm{mL}$, which was a condition that allowed the best differentiation rates. Thus, after $72 \mathrm{~h}$ of cultivation, about $80 \%$ of the cells in the supernatant were in the trypomastigote form.
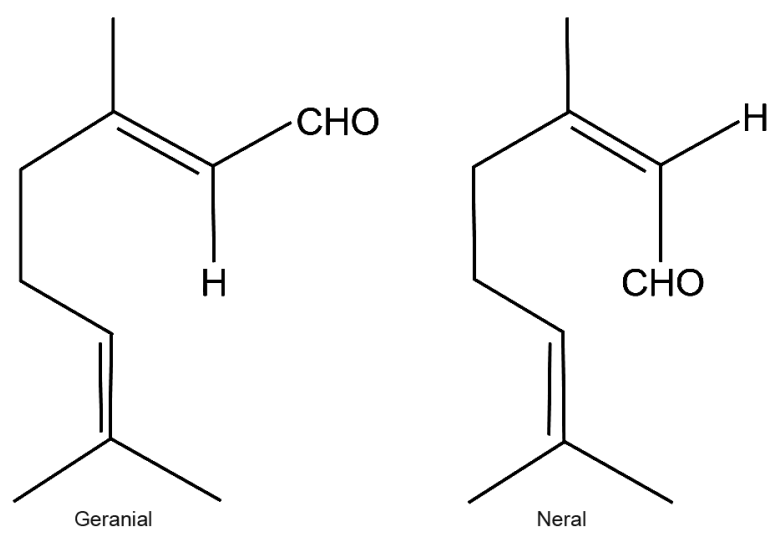

Fig. 1: citral $\left(\mathrm{C}_{10} \mathrm{H}_{16} \mathrm{O}\right.$, molecular mass $\left.152.24 \mathrm{~g} / \mathrm{mol}\right)$ exhibits geometrical isomerism and is a mixture of geranial (citral a, trans form) and neral (citral b, cis form).
Culture supernatants were collected after 24, 48 and $72 \mathrm{~h}$ of incubation in TAU3AAG medium and the number of living epimastigotes and metacyclic trypomastigotes was determined by light microscopy and cell counting using a Neubauer chamber. These evolutive forms could be easily differentiated on morphological grounds because epimastigotes are broad and have a rigid body, whereas trypomastigotes are slim and present a wavy movement of the whole body.

Inhibition of epimastigote-to-trypomastigote differentiation with citral - In the first set of experiments, we only added citral to the stress medium, TAU, and tested whether citral would affect the differentiation process of stressed epimastigotes, which occurs in the TAU3AAG medium. We added $50 \mu \mathrm{g} / \mathrm{mL}$ citral to the TAU medium. This concentration was chosen because a previous study showed that the $\mathrm{IC}_{50} / 24 \mathrm{~h}$ for citral against $T$. cruzi epimastigotes was about $40 \mu \mathrm{g} / \mathrm{mL}$ (Santoro et al. 2007a). After incubation for $2 \mathrm{~h}$ at $28^{\circ} \mathrm{C}$ in this medium, the parasites in the supernatant were observed by light microscopy, collected by centrifugation and transferred to citral-free TAU3AAG medium kept at $28^{\circ} \mathrm{C}$. Culture supernatants were collected after 24,48 and $72 \mathrm{~h}$ of incubation and the number of living epimastigotes and metacyclic trypomastigotes was determined by light microscopy as described above.

In another experiment, epimastigotes were maintained for $2 \mathrm{~h}$ at $28^{\circ} \mathrm{C}$ in citral-free TAU medium and the stressed parasites were transferred to TAU3AAG medium (kept at $28^{\circ} \mathrm{C}$ ) containing different citral concentrations $(20,40,60,80$ or $100 \mu \mathrm{g} / \mathrm{mL})$. Culture supernatants were collected after 24,48 and $72 \mathrm{~h}$ of incubation and the number of living epimastigotes and metacyclic trypomastigotes was determined by light microscopy as described above.

To examine whether fully differentiated metacyclic trypomastigotes were susceptible to citral, trypomastigotes were obtained after a normal differentiation process in TAU3AAG medium. After $72 \mathrm{~h}$, the resulting trypomastigotes $\left(8 \times 10^{5}\right.$ cells $\left./ \mathrm{mL}\right)$ were resuspended in 24 well plates at $4 \times 10^{5}$ cells $/ 500 \mu \mathrm{L}$ TAU3AAG medium per well. Each well contained 0, 20, 40, 60 or $80 \mu \mathrm{g} / \mathrm{mL}$ citral. After a $24 \mathrm{~h}$ incubation, the number of living trypomastigotes was assessed by cell counting in a Neubauer chamber to determine the percent of parasite lysis.

To determine whether the effect of citral was reversible, parasites (epimastigotes plus trypomastigotes) were obtained by differentiation in TAU3AAG medium containing $40 \mu \mathrm{g} / \mathrm{mL}$ citral. After $48 \mathrm{~h}$ of incubation in this medium, the parasites were resuspended in 24-well plates at $1 \times 10^{5}$ cells $/ \mathrm{mL}$ in citralfree LIT medium (1 mL per well) The number of living epimastigotes in the cultures was assessed daily by cell counting in a Neubauer chamber.

All of these tests were performed in triplicate in three independent experiments.

Electron microscopy - Culture flasks with differentiating epimastigotes in TAU3AAG medium containing $30 \mu \mathrm{g} / \mathrm{mL}$ citral were incubated for $24 \mathrm{~h}$. After incubation, the supernatant was collected and the free-swimming parasites were obtained by centrifugation at 5,500 $g$ for 
$5 \mathrm{~min}$. To collect the remaining adhered parasites, about $5 \mathrm{~mL}$ of TAU3AAG medium was added to the empty flasks, which were vigorously shaken in a vortex for about $2 \mathrm{~min}$. This medium was collected and the procedure was repeated twice. These three aliquots were pooled and centrifuged at 5,500 $\mathrm{g}$ for $5 \mathrm{~min}$, which resulted in a pellet of adhered epimastigotes. Free-swimming and adhered parasites were then processed for electron microscopy. Control cultures without citral were also analyzed.

For scanning electron microscopy (SEM), adhered and free-swimming parasites were fixed for 30 min with $2.5 \%$ glutaraldehyde in $0.1 \mathrm{M}$ phosphate buffer and then adhered for $10 \mathrm{~min}$ to glass coverslips coated with $0.1 \%$ poly-L-lysine. The samples were washed in buffer and post-fixed for $15 \mathrm{~min}$ with $1 \%$ osmium tetroxide in $0.1 \mathrm{M}$ cacodylate buffer ( $\mathrm{pH}$ 7.2). Thereafter, the samples were dehydrated in graded acetone, critical-point dried and mounted on SEM stubs. The samples were coated with a 20 -nm thick gold layer and examined in a Jeol JSM6360LV scanning electron microscope.

For transmission electron microscopy, adhered and free-swimming parasites were washed in $0.1 \mathrm{M}$ phosphate buffer ( $\mathrm{pH} 7.2$ ) and fixed for $30 \mathrm{~min}$ with $2.5 \%$ glutaraldehyde in $0.1 \mathrm{M}$ phosphate buffer. The cells were then washed once with $0.1 \mathrm{M}$ phosphate buffer, once with $0.1 \mathrm{M}$ cacodylate buffer and post-fixed for $15 \mathrm{~min}$ with $1 \%$ osmium tetroxide, $0.8 \%$ potassium ferricyanide and $5 \mathrm{mM} \mathrm{CaCl}_{2}$ in $0.1 \mathrm{M}$ cacodylate buffer ( $\mathrm{pH}$ 7.2). Cells were rinsed in buffer, dehydrated in graded acetone, infiltrated overnight in a $100 \%$ acetone/PolyBed 812 mixture (1:1) and embedded for $72 \mathrm{~h}$ at $60^{\circ} \mathrm{C}$ in PolyBed 812 (PolySciences, Warrington, PA, USA) resin. Ultrathin sections were stained with 5\% uranyl acetate and lead citrate and observed in a Jeol 1200EXII transmission electron microscope.

\section{RESULTS}

Citral added to TAU medium does not influence metacyclogenesis - First, we analyzed whether $50 \mu \mathrm{g} /$ $\mathrm{mL}$ citral added to epimastigotes maintained in the stress medium, TAU, would influence the metacyclogenesis process. The results showed that this concentration of citral did not have an effect on the differentiation rate. Indeed, about $80 \%$ of the cells were in the trypomastigote form $48-72 \mathrm{~h}$ after being transferred to citral-free TAU3AAG (differentiation) medium. This differentiation rate was similar to the rate in the controls. Light microscopy showed that most cells from control and citral-treated culture supernatants appeared as long epimastigotes, which confirmed that citral treatment for $2 \mathrm{~h}$ in TAU medium had no effect on parasite morphology and differentiation potential.

Citral added to TAU $3 A A G$ medium inhibits metacyclogenesis in a concentration-dependent manner - A different result was obtained when citral was added only to the differentiation medium, TAU3AAG. Although no effect was observed at $20 \mu \mathrm{g} / \mathrm{mL}$, metacyclogenesis was almost totally abolished at $40 \mu \mathrm{g} / \mathrm{mL}$ after 24,48 or $72 \mathrm{~h}$ of incubation. Higher concentrations $(60,80$ or $100 \mu \mathrm{g} / \mathrm{mL})$ induced $100 \%$ cell lysis. We determined that the $\mathrm{IC}_{50} / 24$ $\mathrm{h}$ of citral was $30.8 \mu \mathrm{g} / \mathrm{mL}$ (Fig. 2A). An additional experi- ment, which was performed with $30 \mu \mathrm{g} / \mathrm{mL}$ citral added to the TAU3AAG medium, confirmed the estimated calculation. Indeed, metacyclogenesis was inhibited by about $54 \%$ and $45 \%$ after $24 \mathrm{~h}$ and $48 \mathrm{~h}$, respectively.
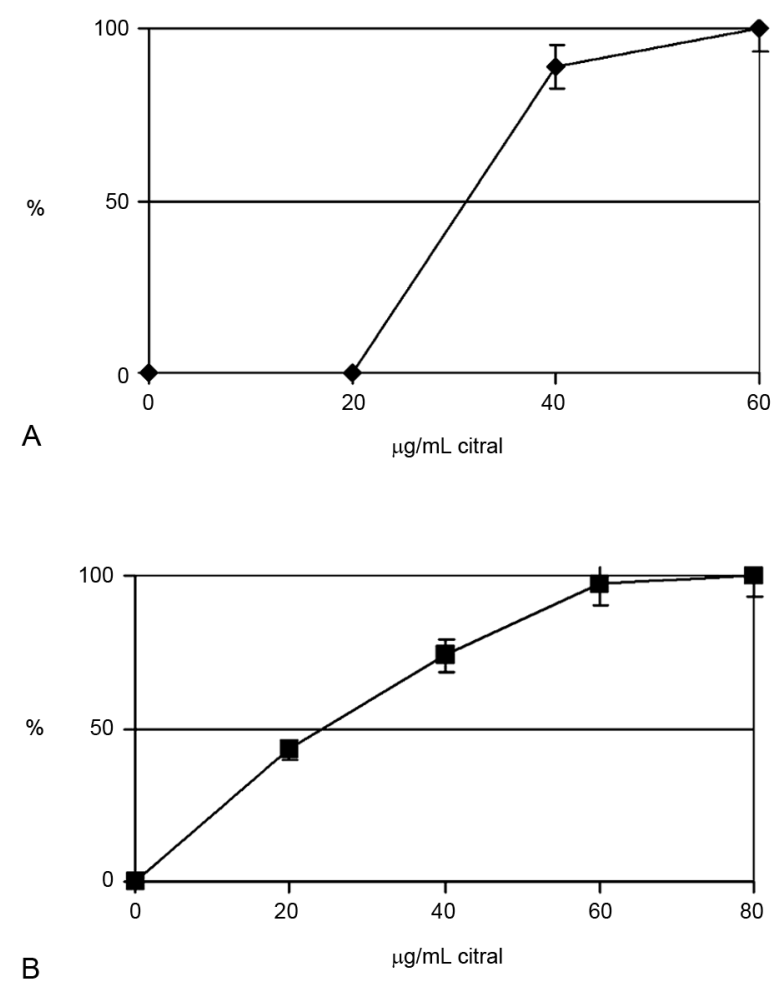

B

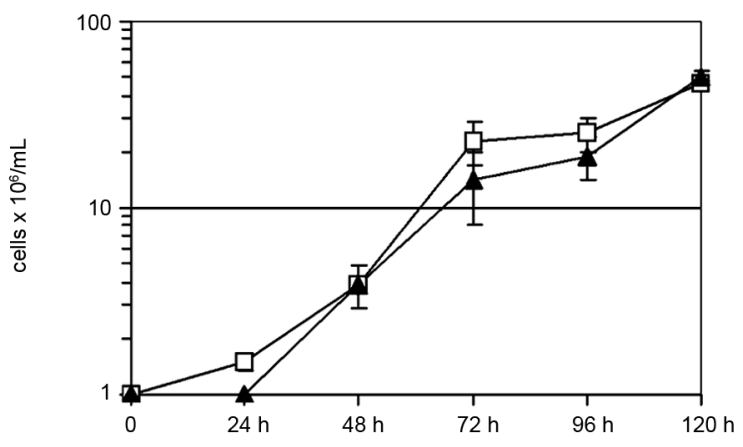

C

Fig. 2A: estimative of the $\mathrm{IC}_{50} / 24 \mathrm{~h}$ (concentration that inhibited metacyclogenesis in 50\% after incubation for $24 \mathrm{~h}$ ) of citral in triatomine artificial urine (TAU)3AAG medium. The value obtained was about $30.8 \mu \mathrm{g} /$ $\mathrm{mL}$. Each point represents the mean and standard deviation (SD) values; B: estimative of $\mathrm{IC}_{50} / 24 \mathrm{~h}$ for metacyclic trypomastigotes incubated for $24 \mathrm{~h}$ in TAU3AAG medium containing different citral concentrations. The $\mathrm{IC}_{50} / 24 \mathrm{~h}$ was estimated as about $24.5 \mu \mathrm{g} / \mathrm{mL}$; C: reversibility assay. Parasites were pre-treated for $48 \mathrm{~h}$ with $40 \mu \mathrm{g} / \mathrm{mL}$ citral in TAU3AAG medium and then transferred to citral-free liver infusion tryptose medium. Epimastigote growth in the cultures was then estimated by daily cell counting in Neubauer chamber. Each point represents the mean and SD values. $\square$ : control; $\mathbf{\Delta}$ : parasites from cultures containing $40 \mu \mathrm{g} / \mathrm{mL}$ citral. 
Treatment with citral blocks cell differentiation but does not affect epimastigote adhesion - We used light microscopy to examine living, free-swimming parasites from cultures maintained for $24 \mathrm{~h}$ in TAU3AAG medium with $40 \mu \mathrm{g} / \mathrm{mL}$ citral. Although most cells in the supernatant of the control medium displayed the characteristic morphology of metacyclic trypomastigotes, most cells in the supernatant of cultures treated with $40 \mu \mathrm{g} / \mathrm{mL}$ citral kept the epimastigote form. The adhesion process, however, was not affected and similar numbers of adhered parasites were observed in treated and untreated culture flasks (data not shown). Nevertheless, parasites from treated cultures presented morphological alterations and showed rounded bodies or signs of cell extraction when compared with the controls. Although citral treatment did not block adhesion, these results indicate that citral treatment affected factors that trigger the $T$. cruzi differentiation process.

Metacyclic trypomastigotes are more susceptible to citral than epimastigotes - To determine whether metacyclic trypomastigotes were more susceptible to citral than epimastigotes, trypomastigotes were obtained after a normal differentiation process for $72 \mathrm{~h}$ in TAU3AAG medium and incubated for $24 \mathrm{~h}$ in TAU3AAG medium containing $0,20,40,60$ or $80 \mu \mathrm{g} / \mathrm{mL}$ citral. There was a concentration-dependent effect and $60 \mu \mathrm{g} / \mathrm{mL}$ citral killed almost all of the parasites. The $\mathrm{IC}_{50} / 24 \mathrm{~h}$ was estimated to be $24.5 \mu \mathrm{g} / \mathrm{mL}$ (Fig. 2B).

Effect of citral on epimastigotes is reversible - Although citral effectively inhibited the epimastigote to trypomastigote differentiation, its effect on epimastigote growth was reversible. Epimastigote growth resumed when parasites treated with $40 \mu \mathrm{g} / \mathrm{mL}$ citral in TAU3AAG medium were washed in LIT medium and incubated in citral-free LIT medium (Fig. 2C).

Citral induces morphological alterations during $T$. cruzi differentiation - SEM of differentiating parasites treated with $30 \mu \mathrm{g} / \mathrm{mL}$ citral (corresponding to the $\mathrm{IC}_{50} / 24$ $\mathrm{h}$ value) confirmed the results obtained by light microscopy. Most treated epimastigotes, whether they were in the supernatant (Fig. 3B, C) or adhered to the walls of the flasks (Fig. 3E, F), presented a rounded body, whereas the control cells had an elongated body (Fig. 3A, D).
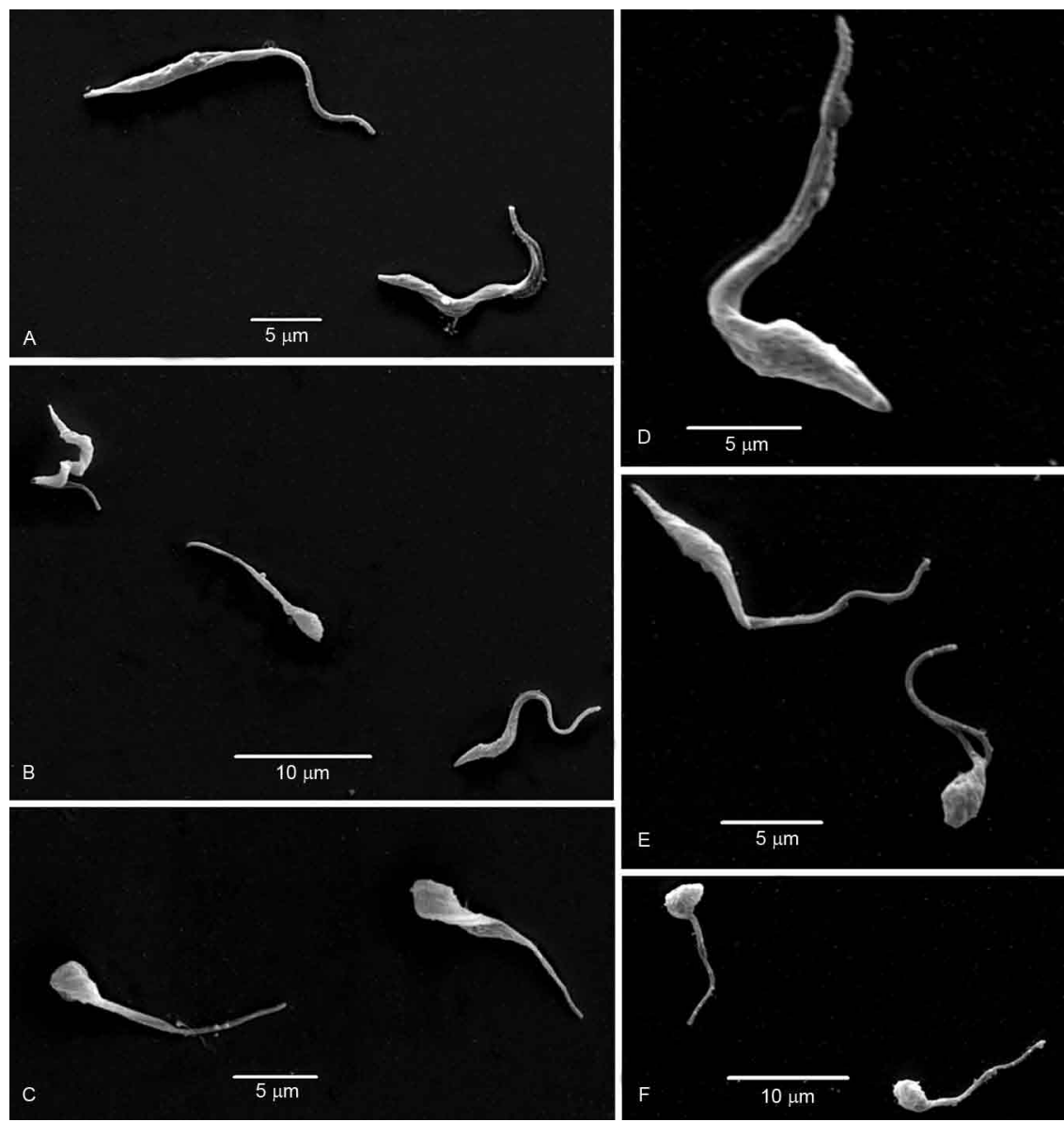

Fig. 3: scanning electron microscopy of parasites from the supernatant (A-C) or adhered to the flask walls (D-F) from cultures kept in triatomine artificial urine (TAU)3AAG medium for $24 \mathrm{~h}$ (A, D) controls. A: both epimastigote and trypomastigote forms can be seen; D: is a higher magnification of an epimastigote form; B-D, F: epimastigotes from cultures with $30 \mu \mathrm{g} / \mathrm{mL}$ citral. Note that treated cells (both in the supernatant and adhered to the substrate) are rounded and shorter. 
Transmission electron microscopy (Fig. 4A-D) showed that incubation for $24 \mathrm{~h}$ in medium containing $30 \mu \mathrm{g} / \mathrm{mL}$ citral caused the parasites in the supernatant to have a rounded form with swelling of the mitochondrion and a loose arrangement of the kDNA network (Fig. 4C). Adhered parasites that retained the epimastigote form showed few morphological alterations, except for the presence of a higher number of cytoplasmic vacuoles (Fig. 4D).

\section{DISCUSSION}

C. citratus, popularly known as citronella grass or lemongrass, is a perennial grass that is widespread throughout the world. The anti-microbial and anti-fungal activities of lemongrass essential oil, which are primarily due to its main constituent citral (Onawunmi et al. 1984), have been known for a long time (Kurita et al. 1981, Mishra \& Dubey 1994). The present study was the first to show the inhibitory effects of citral on the differentiation process (metacyclogenesis) of $T$. cruzi in vitro. Our data demonstrated that incubation with citral decreased epimastigote differentiation efficiency in vitro, which resulted in cultures with low numbers of trypomastigotes. Furthermore, epimastigote adhesion was not blocked with the citral treatment, which suggested that citral affects factors that trigger the $T$. cruzi differentiation process. Therefore, citral may be useful in experiments analyzing the molecules involved in $T$. cruzi differentiation. During in vivo metacyclogenesis, adhesion of epimastigotes to a substrate was thought to be a prerequisite for differentiation into metacyclic trypomastigotes (Bonaldo et al. 1988). The role of adhesion in stimulating differentiation remains unknown, but both adhesion and cell differentiation have been shown to be initiated by a nutritional stress stimulus (Figueiredo et al. 2000).

Addition of $50 \mu \mathrm{g} / \mathrm{mL}$ citral to TAU stress medium containing epimastigotes did not influence the metacyclogenesis process when the treated parasites were transferred to citral-free TAU3AAG medium. Because the TAU medium with epimastigotes/citral was diluted at 1:100 in TAU3AAG, there was a final concentration of $0.5 \mu \mathrm{g} / \mathrm{mL}$ citral in TAU3AAG, which apparently had no influence on the differentiation process. Our morphological data showed that incubation for $2 \mathrm{~h}$ in citral-TAU medium did not result in any morphological alteration of the parasites. The incubation time, however, may not have been long enough to cause any metabolic disturbance in the cells. When citral $(20-100 \mu \mathrm{g} / \mathrm{mL})$ was added directly to the TAU3AAG medium, we observed a strong concentration-dependent influence on the parasites.

Interestingly, a previous study on the incubation of T. cruzi epimastigotes and bloodstream trypomastigotes with lemongrass essential oil and citral also showed a concentration-dependent effect (Santoro et al. 2007a). For epimastigotes, the $\mathrm{IC}_{50} / 24 \mathrm{~h}$ value was $126.5 \mu \mathrm{g} / \mathrm{mL}$ for the oil and $42 \mu \mathrm{g} / \mathrm{mL}$ for citral (Santoro et al. 2007a). For bloodstream trypomastigotes, $\mathrm{IC}_{50} / 24 \mathrm{~h}$ values were $15.5 \mu \mathrm{g} / \mathrm{mL}$ for the oil and $14.2 \mu \mathrm{g} / \mathrm{mL}$ for citral. Almost $100 \%$ trypomastigote lysis was obtained with $50 \mu \mathrm{g} / \mathrm{mL}$ citral (Santoro et al. 2007a). The present study observed about $90 \%$ cell lysis for metacyclic trypomastigotes after treatment with $60 \mu \mathrm{g} / \mathrm{mL}$ citral and the $\mathrm{IC}_{50} / 24 \mathrm{~h}$ was estimated to be $24.5 \mu \mathrm{g} / \mathrm{mL}$, which confirmed the results of the Santoro et al. (2007a). Trypomastigotes were more susceptible to citral than epimastigotes and bloodstream trypomastigotes were more susceptible to citral than in vitro-derived metacyclic trypomastigotes. Because epimastigotes, bloodstream trypomastigotes and metacyclic trypomastigotes have different metabolisms and different glycoconjugate compositions at the cell membrane (de Andrade et al. 1991, de Souza 2008), these different susceptibilities could be due to different cell permeability rates for citral or different cellular targets.

Our data showed that treatment with citral induced ultrastructural alterations in the parasites, such as rounding of the body and cell vacuolization. An important characteristic of essential oils and their components is their hydrophobicity (Burt 2004). Indeed, hydrophobicity allows the essential oils to permeate the cell membrane and kill $T$. cruzi parasites by affecting cytoplasmic metabolic pathways or organelles (Santoro et al. 2007a). Essential oils permeate the cell membranes and disrupt the structure of the different layers of membrane polysaccharides, fatty acids and phospholipids, which permeabilizes the membranes (Bakkali et al. 2008). Essential oil cytotoxicity appears to include membrane damage, which leads to the leakage of macromolecules and lysis (Juven et al. 1994, Gustafson et al. 1998, Cox et al. 2000, Lambert et al. 2001, Oussalah et al. 2006). Because our microscopy findings indicated that citral treatment resulted in rounding of the parasite body with cell vacuolization, the $T$. cruzi

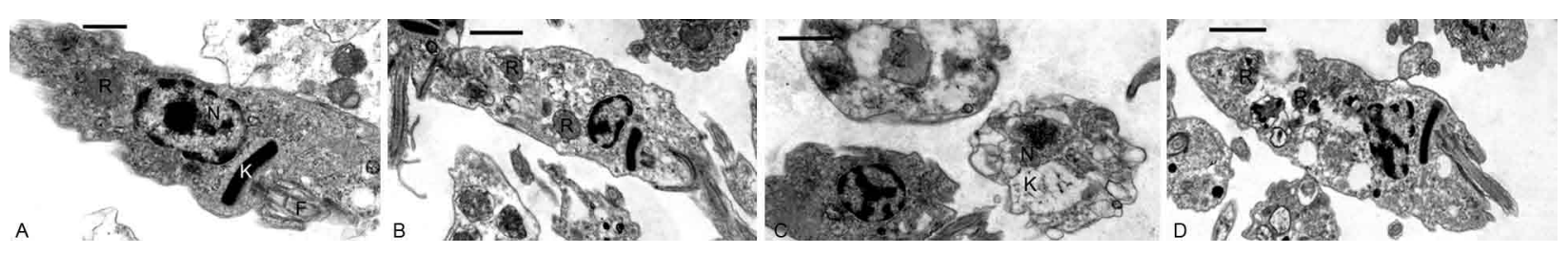

Fig. 4: transmission electron microscopy of epimastigotes from the supernatant (A, C) or adhered to the flask walls (B, D) from cultures kept in triatomine artificial urine (TAU)3AAG medium for $24 \mathrm{~h}$. A-B: control epimastigotes, showing the elongated body and the presence of reservosomes (R). C-D: parasites from cultures treated with $30 \mu \mathrm{g} / \mathrm{mL}$ citral. Note that treated epimastigotes (both in the supernatant and adhered to the substrate) present morphological alterations such rounding of the body, mitochondrial swelling at the kinetoplast region (K) and vacuolization. F: flagellun; N: nucleus. Bars $=5 \mu \mathrm{m}$. 
cell membranes may have been permeabilized by citral, which would lead to organelle toxicities, cytoplasmic leakage and cell lysis.

In eukaryotic cells, studies have shown that essential oils can provoke depolarization of the mitochondrial membranes and permeabilization of the outer and inner mitochondrial membranes, which leads to cell death by apoptosis and necrosis (Yoon et al. 2000, Armstrong 2006). The damaged mitochondria result in changes in electron flow through the electron transport chain, which can produce free radicals that oxidise and damage lipids, proteins and DNA (Bakkali et al. 2008). Because we observed mitochondrial swelling in citral-treated T. cruzi parasites, it is possible that such events may be occurring in this parasite.

Similar growth inhibition results have been described with $C$. citratus essential oil assays of other trypanosomatids. Indeed, studies have demonstrated the in vitro activity of this essential oil against $C$. deanei, with mean $\mathrm{IC}_{50}$ values for symbiont-bearing and symbiont-free strains of 120 and $60 \mu \mathrm{g} / \mathrm{mL}$, respectively (Pedroso et al. 2006). Interestingly, L. amazonensis promastigotes were more sensitive to the essential oil and citral, with $\mathrm{IC}_{50}$ of about 1.7 and $8.0 \mu \mathrm{g} / \mathrm{mL}$, respectively, after $72 \mathrm{~h}$ of incubation (Santin et al. 2009). One study showed that $3.1 \mu \mathrm{M}$ concentrations of neral or geranial (isomers of citral) were effective against epimastigotes of T. cruzi (Saeidnia et al. 2004). Another study showed that citral presented high activity against $T$. cruzi bloodstream trypomastigotes (Santoro et al. 2007a). In addition, recent data demonstrated a concentration-dependent anti-proliferative activity of citral-rich essential oil from $C$. citratus on promastigotes, axenic amastigotes and intracellular amastigotes of L. amazonensis (Santin et al. 2009).

Studies of $T$. cruzi in mouse peritoneal macrophages demonstrated that the use of $C$. citratus essential oil resulted in a selectivity index (the ratio of the $\mathrm{IC}_{50}$ value in the host cell divided by the $\mathrm{IC}_{50}$ value of the parasite) close to two (Santoro et al. 2007a). The expected value for a good drug candidate, however, is greater than 50 (Romanha et al. 2010). Despite the toxicity to mouse macrophages, the testing of citral derivatives appears to be an alternative in the search for new chemotherapeutic drugs.

Data from the literature have shown that the metacyclogenesis process of $T$. cruzi could be inhibited by the topoisomerase II inhibitor ofloxacin (Gonzales-Perdomo et al. 1990), the antitubulin drug trifluralin (Bogitsh et al. 1999), the proteasome inhibitor lactacystin (Cardoso et al. 2008), metallo and cysteine-protease inhibitors (Bonaldo et al. 1991) or mannose (Barbieri et al. 1992). The data from the present paper showed that citral effectively blocked the metacyclogenesis of $T$. cruzi in vitro. In addition, citral killed the resulting metacyclic trypomastigote form, which may have occurred through alterations of membrane permeability. Therefore, citral appears to be a good inhibitory drug candidate for studies on the T. cruzi metacyclogenesis process.

\section{ACKNOWLEDGEMENTS}

To the Centro de Microscopia Eletrônica at the Universidade Federal do Paraná, for the use of the scanning and transmission electron microscopes. All experiments comply with the current laws of Brazil.

\section{REFERENCES}

Armstrong JS 2006. Mitochondrial membrane permeabilization: the sine qua non for cell death. Bioessays 28: 253-260.

Bakkali F, Averbeck S, Averbeck D, Idaomar M 2008. Biological effects of essential oils - a review. Food Chem Toxicol 46: 446-475.

Barbieri MA, Lammel EM, Isola EL, Bertini F 1992. Trypanosoma cruzi: inhibition of metacyclogenesis by mannose. Biochem Biophys Res Commun 187: 108-113.

Bogitsh BJ, Middleton OL, Ribeiro-Rodrigues R 1999. Effects of the antitubulin drug trifluralin on the proliferation and metacyclogenesis of Trypanosoma cruzi epimastigotes. Parasitol Res 85: 475-480.

Bonaldo MC, d'Escoffier LN, Salles JM, Goldenberg S 1991. Characterization and expression of proteases during Trypanosoma cruzi metacyclogenesis. Exp Parasitol 73: 44-51.

Bonaldo MC, Souto-Padron T, de Souza W, Goldenberg S 1988. Cellsubstrate adhesion during Trypanosoma cruzi differentiation. $J$ Cell Biol 106: 1349-1358.

Burt S 2004. Essential oils: their antibacterial properties and potential applications in foods - a review. Int J Food Microbiol 94: 223-253.

Camargo EP 1964. Growth and differentiation of Trypanosoma cruzi. I. Origin of metacyclic trypanosomes in liquid media. Rev Inst Med Trop Sao Paulo 6: 93-100.

Cardoso J, Soares MJ, Menna-Barreto RF, Le Bloas R, Sotomaior V, Goldenberg S, Krieger MA 2008. Inhibition of proteasome activity blocks Trypanosoma cruzi growth and metacyclogenesis. Parasitol Res 103: 941-951.

Cimanga K, Kambu K, Tona L, Apers S, De Bruyne T, Hermans N, Totté J, Pieters L, Vlietinck AJ 2002. Correlation between chemical composition and antibacterial activity of essential oils of some aromatic medicinal plants growing in the Democratic Republic of Congo. J Ethnopharmacol 79: 213-220.

Contreras VT, Araujo-Jorge TC, Bonaldo MC, Thomaz N, Barbosa HS, Meirelles MN, Goldenberg S 1988. Biological aspects of the Dm 28c clone of Trypanosoma cruzi after metacyclogenesis in chemically defined media. Mem Inst Oswaldo Cruz 83: 123-133.

Contreras VT, Salles JM, Thomas N, Morel CM, Goldenberg S 1985. In vitro differentiation of Trypanosoma cruzi under chemically defined conditions. Mol Biochem Parasitol 16: 315-327.

Coura JR, de Castro SL 2002. A critical review on Chagas disease chemotherapy. Mem Inst Oswaldo Cruz 97: 3-24.

Coura JR, Dias JC 2009. Epidemiology, control and surveillance of Chagas disease - 100 years after its discovery. Mem Inst Oswaldo Cruz 104 (Suppl. I): 31-40.

Cox SD, Mann CM, Markham JL, Bell HC, Gustafson JE, Warmington JR, Wyllie SG 2000. The mode of antimicrobial action of the essential oil of Melaleuca alternifolia (tea tree oil). J Appl Microbiol 88: 170-175.

de Andrade AF, Esteves MJ, Angluster J, Gonzales-Perdomo M, Goldenberg S 1991. Changes in cell-surface carbohydrates of Trypanosoma cruzi during metacyclogenesis under chemically defined conditions. J Gen Microbiol 137: 2845-2849.

de Souza W 1984. Cell biology of Trypanosoma cruzi. Int Rev Citol 86: $197-283$.

De Souza W 2008. Electron microscopy of trypanosomes - A historical view. Mem Inst Oswaldo Cruz 103: 313-325.

Figueiredo RC, Rosa DS, Soares MJ 2000. Differentiation of Trypanosoma cruzi epimastigotes: metacyclogenesis and adhesion to substrate are triggered by nutritional stress. J Parasitol 86: 1213-1218. 
Gonzales-Perdomo M, de Castro SL, Meirelles MN, Goldenberg S 1990. Trypanosoma cruzi proliferation and differentiation are blocked by topoisomerase II inhibitors. Antimicrob Agents Chemother 34: 1707-1714.

Gustafson JE, Liew YC, Chew S, Markham J, Bell HC, Wyllie SG, Warmington JR 1998. Effects of tea tree oil on Escherichia coli. Lett Appl Microbiol 26: 194-198.

Ibrahim D 1992. Antimicrobial activity of the essential oil of the local serai, Cymbopogon citratus. J Bioscience 3: 87-90.

Juven BJ, Kanner J, Schved F, Weisslowicz H 1994. Factors that interact with the antibacterial action of thyme essential oil and its active constituents. $J$ Appl Bacteriol 76: 626-631.

Kurita N, Makoto M, Kurane R, Takahara Y, Ichimura K 1981. Antifungal activity of components of essential oils. Agric Biol Chem 45: 945-952.

Lambert RJ, Skandamis PN, Coote PJ, Nychas GJ 2001. A study of the minimum inhibitory concentration and mode of action of oregano essential oil, thymol and carvacrol. J Appl Microbiol 91: 453-462.

Mikus J, Harkenthal M, Steverding D, Reichling J 2000. In vitro effect of essential oils and isolated mono- and sesquiterpenes on Leishmania major and Trypanosoma brucei. Planta Med 66: 366-368.

Mishra AK, Dubey NK 1994. Evaluation of some essential oils for their toxicity against fungi causing deterioration of stored food commodities. Appl Environ Microbiol 60: 1101-1105.

Monzote L, Montalvo AM, Almanonni S, Scull R, Miranda M, Abreu $\mathrm{J} 2006$. Activity of the essential oil from Chenopodium ambrosioides grown in Cuba against Leishmania amazonensis. Chemotherapy 52: 130-136.

Onawunmi GO 1989. Evaluation of the antimicrobial activity of citral. Let Appl Microbiol 9: 105-108.

Onawunmi GO, Yisak WA, Ogunlana EO 1984. Antibacterial constituents in the essential oil of Cymbopogon citratus (DC.) Stapf. J Ethnopharmacol 12: 279-286.

Oussalah M, Caillet S, Lacroix M 2006. Mechanism of action of Spanish oregano, Chinese cinnamon, and savory essential oils against cell membranes and walls of Escherichia coli $\mathrm{O} 157: \mathrm{H} 7$ and Listeria monocytogenes. J Food Prot 69: 1046-1055.

Pedroso RB, Ueda-Nakamura T, Dias Filho BP, Cortez DAG, Cortez LER, Morgado-Diaz JA, Nakamura CV 2006. Biological activities of essential oil obtained from Cymbopogon citratus on Crithidia deanei. Acta Protozool 45: 231-240.

Romanha AJ, de Castro SL, Soeiro MNC, Lannes-Vieira J, Ribeiro I, Talvani A, Bourdin B, Blum B, Olivieri B, Zani C, Spadafora C, Chiari E, Chatelain E, Chaves G, Calzada JE, Bustamante JM,
Freitas-Junior LH, Romero LI, Bahia MT, Lotrowska M, Soares M, Andrade SG, Armstrong T, Degrave W, Andrade ZA 2010. In vitro and in vivo experimental models for drug screening and development for Chagas disease. Mem Inst Oswaldo Cruz 105: 233-238.

Saeidnia S, Gohari AR, Uchiyama N, Ito M, Honda G, Kiuchi F 2004. Two new monoterpene glycosides and trypanocidal terpenoids from Dracocephalum kotschyi. Chem Pharm Bull (Tokyo) 52: $1249-1250$.

Santin MR, dos Santos AO, Nakamura CV, Dias Filho BP, Ferreira IC, Ueda-Nakamura T 2009. In vitro activity of the essential oil of Cymbopogon citratus and its major component (citral) on Leishmania amazonensis. Parasitol Res 105: 1489-1496.

Santoro GF, Cardoso MG, Guimarães LG, Freire JM, Soares MJ 2007a. Anti-proliferative effect of the essential oil of Cymbopogon citratus (DC) Stapf (lemongrass) on intracellular amastigotes, bloodstream trypomastigotes and culture epimastigotes of Trypanosoma cruzi (Protozoa: Kinetoplastida). Parasitology 134: 1649-1656.

Santoro GF, Cardoso MG, Guimarães LG, Mendonça LZ, Soares MJ 2007b. Trypanosoma cruzi: activity of essential oils from Achillea millefolium L., Syzygium aromaticum L. and Ocimum basilicum L. on epimastigotes and trypomastigotes. Exp Parasitol 116: 283-290.

Santoro GF, das Graças Cardoso M, Guimarães LG, Salgado AP, Menna-Barreto RF, Soares MJ 2007c. Effect of oregano (Origanum vulgare L.) and thyme (Thymus vulgaris L.) essential oils on Trypanosoma cruzi (Protozoa: Kinetoplastida) growth and ultrastructure. Parasitol Res 100: 783-790.

Tchoumbougnang F, Zollo PH, Dagne E, Mekonnen Y 2005. In vivo antimalarial activity of essential oils from Cymbopogon citratus and Ocimum gratissimum on mice infected with Plasmodium berghei. Planta Med 71: 20-23.

Urbina JA 2009. New advances in the management of a long-neglected disease. Clin Infect Dis 49: 1685-1687.

Valentin A, Pélissier Y, Benoit F, Marion C, Kone D, Mallie M, Bastide JM, Bessière JM 1995. Composition and antimalarial activity in vitro of volatile components of Lippia multiflora. Phytochemistry 40: 1439-1442.

Viollon C, Chaumont JP 1994. Antifungal properties of essential oils and their main components upon Cryptococcus neoformans. Mycopathologia 128: 151-153.

Wannissorn B, Jarikasem S, Soontorntanasart T 1996. Antifungal activity of lemon grass oil and lemon grass oil cream. Phytother Res 10: 551-554.

Yoon HS, Moon SC, Kim ND, Park BS, Jeong MH, Yoo YH 2000. Genistein induces apoptosis of RPE-J cells by opening mitochondrial PTP. Biochem Biophys Res Commun 276: 151-156. 